\title{
Cytomegalovirus Viremia in Renal Transplant Recipients After Influenza Vaccination
}

\author{
Akshay M. Khatri ${ }^{1}$, Ilan Berlinrut ${ }^{1}$, Robin Koshy ${ }^{1}$, Madhu Bhaskaran ${ }^{2}$ \\ 1. Infectious Diseases, Northwell Health, Manhasset, USA 2. Nephrology and Transplant Nephrology, Northwell \\ Health, Manhasset, USA
}

Corresponding author: Akshay M. Khatri, akshay1210@gmail.com

\begin{abstract}
Vaccination with the inactivated influenza vaccine is routinely recommended for all patients before and after transplant, with reduction in complications noted in transplant recipients. The vaccine is relatively well tolerated with few mild side effects. Cytomegalovirus (CMV) infection can reactivate in both solid organ transplant and hematopoietic stem cell transplant recipients, with some patients progressing to disease. There are multiple factors known to contribute to reactivation and subsequent CMV disease, however vaccination has not been reported as a specific risk factor.
\end{abstract}

We report on two renal transplant recipients who were seen to develop CMV viremia and CMV disease after receiving the Influenza vaccine. We review the literature regarding viremia occurring after vaccination in HIV patients (a similar group of immunocompromised patients).

Received 07/17/2020

Review began 07/22/2020 Review ended 07/28/2020 Published 08/12/2020

๑) Copyright 2020 Khatri et al. This is an open access article distributed under the terms of the Creative Commons Attribution License CC-BY 4.0., which permits unrestricted use, distribution, and reproduction in any medium, provided the original author and source are credited.
Categories: Allergy/Immunology, Infectious Disease, Transplantation Keywords: cytomegalovirus (cmv), influenza vaccine, renal transplant, viremia

\section{Introduction}

The inactivated Influenza vaccine is recommended in all solid organ transplant recipients (SOTRs) and it can be administered either before or one month after transplantation [1]. In SOTRs, it was associated with a decrease in severity of influenza disease (as determined by occurrence of pneumonia and incidence of intensive care unit admission). The vaccine is relatively well tolerated - there have been reports of mild reactions, with some vaccine strains being associated with risk of rejection [1].

Cytomegalovirus (CMV) can reactivate in both solid organ transplant and hematopoietic stem cell transplant recipients $[2,3]$. There are multiple patient- and therapy-related factors known to contribute to reactivation and subsequent CMV disease [2-6].

Vaccination has reported to cause viremia with human immunodeficiency virus (HIV) in patients who are HIV-infected, even those who are on potent anti-retroviral therapy (ART) [7, 8]. Despite the extensive research, vaccination has not been reported to be a risk factor for CMV viremia in transplant recipients.

In this case report, we describe two cases of kidney transplant recipients who received the influenza vaccine and developed cytomegalovirus (CMV) viremia thereafter. Due to the paucity of literature regarding viremia after vaccination in transplant recipients, we review the studies reporting viremia occurring after vaccination in HIV patients (a similar group of immunocompromised patients).

\section{Case Presentation}

\section{Patient 1}

A 50-year-old female with past medical history of hypertension, autosomal dominant polycystic kidney disease and end-stage renal disease (on hemodialysis) underwent a renal transplant from a living unrelated donor in June 2016.

She received the influenza vaccine in November 2017 at the outpatient transplant nephrology clinic. She presented to her next appointment eight days later with complaints of fevers with chills, night sweats, lethargy, headaches, myalgias, nausea, anorexia, left-sided pleuritic chest pain and multiple episodes of watery, non-bloody diarrhea. She was directed to the emergency department for further evaluation.

She denied sick contacts, recent travel, medication changes or medication non-compliance. At the time of admission, she was on prednisone $5 \mathrm{mg}$ PO (oral) QD, mycophenolate mofetil (MMF) $360 \mathrm{mg}$ PO QID, tacrolimus $0.5 \mathrm{mg}$ PO BID.

Her vitals on admission were significant for temperature $101.7 \mathrm{~F}$, heart rate $100 /$ minute, blood pressure 


\section{Cureus}

118/79 mm Hg, respirations 18/minute and oxygen saturation 98\% on room air. Physical exam revealed no acute abnormalities.

Admission labs were significant for white blood cell (WBC) 2,070/ $\mathrm{mm}^{3}$ [normal range (N): 3,800$\left.10,500 / \mathrm{mm}^{3}\right]$, absolute neutrophil count (ANC) $1,865 / \mathrm{mm}^{3}$ [N: $\left.1,800-7,400 / \mathrm{mm}^{3}\right]$, lymphocyte count $500 / \mathrm{mm}^{3}$ [N: $\left.1,000-3,300 / \mathrm{mm}^{3}\right]$, platelets $108,000 / \mathrm{mm}^{3}\left[\mathrm{~N}: 150,000-400,00 / \mathrm{mm}^{3}\right]$, aspartate transaminase (AST) $81 \mathrm{U} / 1$ [N: 10-40 U/l], alanine transaminase (ALT) $87 \mathrm{U} / 1$ [N: 10-45 U/1], alkaline phosphatase (ALP) 137 $\mathrm{U} / 1$ [N: 40-120 U/1] and normal renal function. Electrocardiogram revealed sinus rhythm with no acute changes. Chest radiography and computed tomography (CT) ruled out the presence of pneumonia. Abdominal ultrasound showed polycystic liver and kidneys, contracted gallbladder with negative sonographic Murphy's sign. CT of the abdomen and pelvis confirmed polycystic liver and kidneys, as well as mural thickening of ascending colon with mild surrounding inflammatory changes (suggestive of colitis) (Figures 1,2).

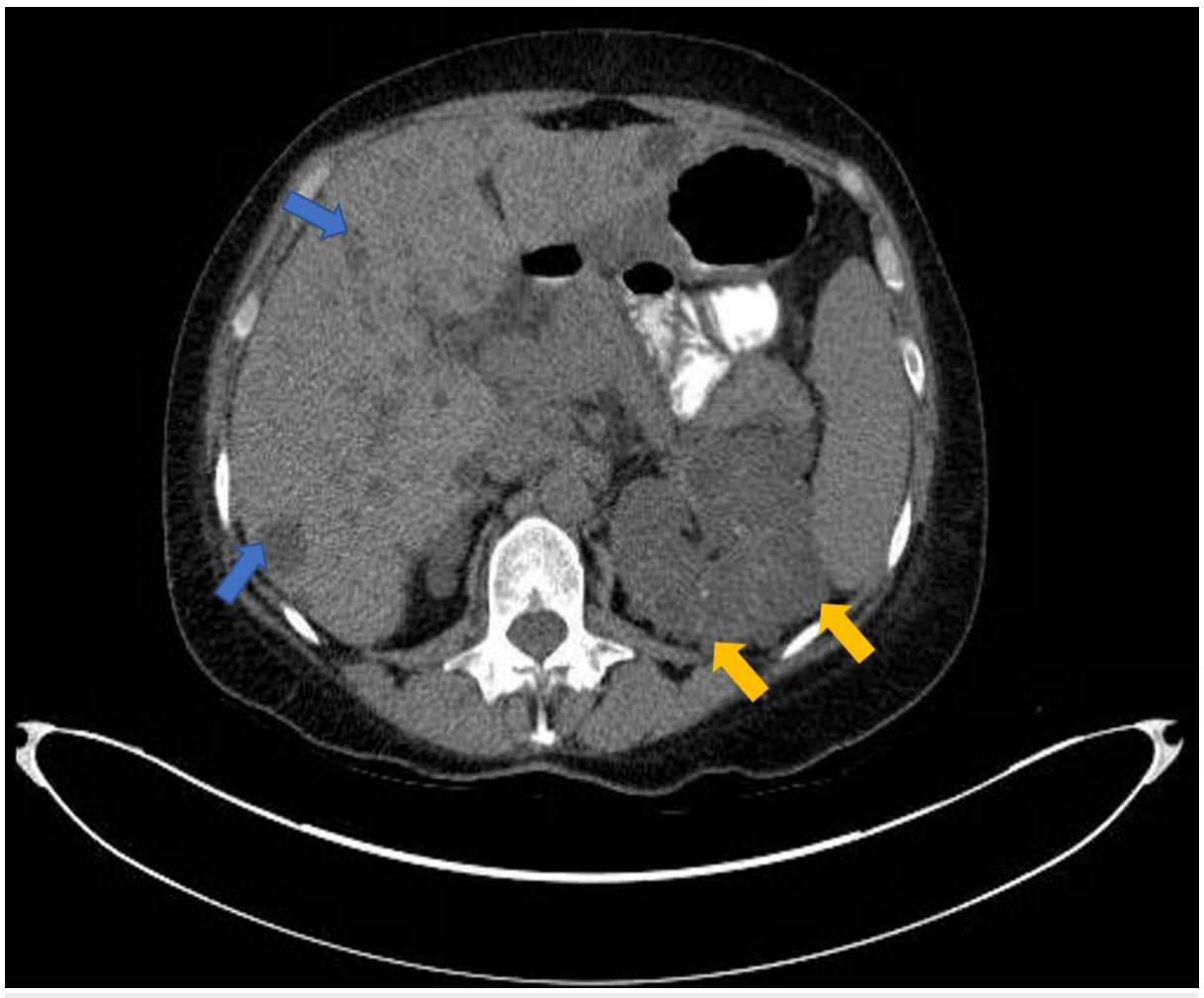

FIGURE 1: Computed tomography (CT) scan of abdomen and pelvis showing presence of cysts in liver (blue arrows) and cysts in the kidney (yellow arrows) 


\section{Cureus}

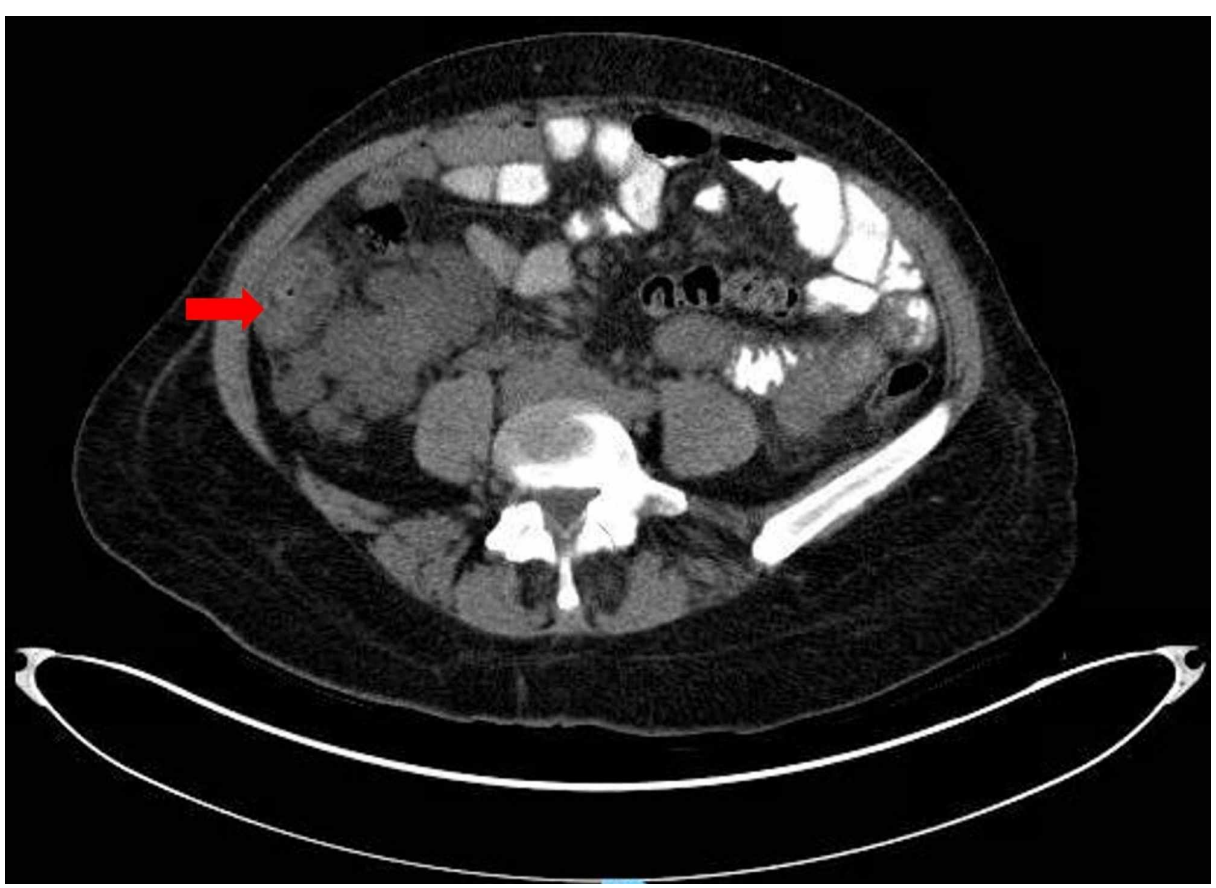

FIGURE 2: Computed tomography (CT) scan of abdomen and pelvis showing thickening of wall of ascending colon with mild inflammatory changes (red arrow), suggestive of colitis of the ascending colon

Urinalysis was not suggestive of infection. Respiratory viral panel multiplex test was negative. Clostridium difficile toxin test was negative. Stool cultures were negative. Stool microscopy was negative for ova and parasites. Urine cultures revealed Escherichia coli $(10,000-49,000 \mathrm{CFU} / \mathrm{ml})$ combined with normal urogenital flora. Blood cultures revealed no growth. Testing for acute hepatitis A, B and C viruses was negative. Epstein-Barr virus serology revealed prior infection. BK virus DNA, Parvovirus B19 DNA and adenovirus DNA were not detected by specific polymerase chain reaction (PCR) tests.

Infectious diseases service was consulted. Given the presence of leukopenia, thrombocytopenia, transaminitis and multi-systemic symptoms, there was concern for an ongoing viral process. She was started on valganciclovir $900 \mathrm{mg}$ PO BID for presumed CMV disease, with intravenous fluid support. The E. coli in the urine was thought to be a colonization and she was successfully monitored off antibiotics.

She continued to have persistent fevers and diarrhea, with worsening leukopenia (lowest WBC count $1700 / \mathrm{mm}^{3}$ with lowest ANC $800 / \mathrm{mm}^{3}$ ), thrombocytopenia (nadir $86,000 / \mathrm{mm}^{3}$ ) and liver function abnormalities (AST 139 U/l, ALT 135 U/l, ALP 167 U/). Given the persistent symptoms and worsening laboratory parameters, MMF was discontinued. Serum CMV PCR testing revealed 154,697 IU/ml (5.19 $\log 10$ $\mathrm{IU} / \mathrm{ml})$ [lower limit of assay detection $60 \mathrm{IU} / \mathrm{ml}(1.78 \log 10 \mathrm{IU} / \mathrm{ml})]$. Gastroenterology service was consulted for worsening liver function abnormalities and they attributed the clinical picture to systemic CMV infection.

She had clinical improvement, with improving CMV PCR tests [504 IU/ml (2.70 log $10 \mathrm{IU} / \mathrm{ml})]$ after 12 days of antiviral therapy. She was discharged on the twelfth day of hospital stay, with recovery of WBC count to $5,600 / \mathrm{mm}^{3}$ and platelets $147,000 / \mathrm{mm}^{3}$.

She was followed up by in the outpatient transplant nephrology and infectious diseases clinics. CMV PCR was negative 60 days after initiation of antiviral therapy and she was restarted on a lower dose of MMF. After the second negative CMV PCR a week later, MMF dose was increased and valganciclovir was decreased to prophylactic dosing. She received valganciclovir for a total of 87 days.

\section{Patient 2}

A 62-year-old female with past medical history of endometriosis, hypertension, chronic kidney disease (likely from anti-inflammatory drug use for management of endometriosis) was being followed in the transplant nephrology clinic. She received a deceased donor kidney transplant in 1998 that failed in March 2018 and was subsequently on hemodialysis. She received a second renal transplant from a deceased unrelated donor in June 2019. 
She received the Influenza vaccine at the end of September 2019. On routine outpatient labs performed a week later, she was noted to have detectable CMV viral levels $[4,983 \mathrm{IU} / \mathrm{ml}(3.70 \log 10 \mathrm{IU} / \mathrm{ml})]$ without any symptoms. The levels continued to rise over the course of two months [214,823 IU $/ \mathrm{ml}(5.33 \log 10 \mathrm{IU} / \mathrm{ml})]$, with no improvement after switching from valganciclovir $450 \mathrm{mg}$ QD to valganciclovir $900 \mathrm{mg}$ QD. She was noted to have worsening leukopenia (WBC $1,260 / \mathrm{mm}^{3}$ ), so she was admitted for further management.

On admission, she reported multiple episodes of non-bloody, foul-smelling diarrhea. She denied sick contacts, recent travel, medication changes or medication non-compliance. Her home medications consisted of tacrolimus ER $8 \mathrm{mg}$ QD, prednisone $5 \mathrm{mg}$ QD, MMF $1000 \mathrm{mg}$ BID, sulfamethoxazole-trimethoprim singlestrength tablet QOD, valganciclovir $450 \mathrm{mg}$ QD.

She was hemodynamically stable on examination. Physical examination revealed no abnormalities.

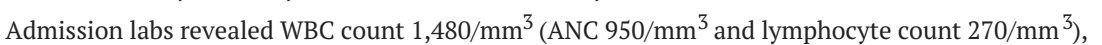
hemoglobin $11.1 \mathrm{~g} / \mathrm{dl}(\mathrm{N}: 13-17 \mathrm{~g} / \mathrm{dL}$ ), blood urea nitrogen (BUN) $20 \mathrm{mg} / \mathrm{dL}$ [N: 7-23 mg/dL], creatinine 1.53 $\mathrm{mg} / \mathrm{dl}$ [N: 0.50-1.30 mg/dL], ALP $124 \mathrm{U} / \mathrm{l}$. Chest radiograph revealed clear lungs. BK virus and Parvovirus B19 DNA PCR tests were negative.

MMF and valganciclovir was held on admission. Infectious diseases service was consulted and she was started on renally-dosed intravenous (IV) ganciclovir ( $2.5 \mathrm{mg} / \mathrm{kg}$ QD) and letermovir $480 \mathrm{mg}$ QD PO. Given the lack of response to outpatient valganciclovir therapy, a sample was sent for CMV resistance testing. With improvement in her creatinine clearance, the ganciclovir dosing was subsequently adjusted. WBC nadir during the hospital stay was $1,450 / \mathrm{mm}^{3}$ (ANC $780 / \mathrm{mm}^{3}$ ), with subsequent recovery due to intravenous antivirals and one dose of filgrastim.

CMV resistance tests revealed the presence of two different populations of virus - wild type and a strain exhibiting resistance at $\mathrm{M} 460 \mathrm{~V}$ and $\mathrm{C603 \textrm {W }}$ (two out of seven mutations conferring resistance to ganciclovir). No resistance was noted to cidofovir or foscarnet. She was discharged on IV ganciclovir and oral letermovir. The final duration of therapy would be determined by outpatient follow-up with infectious diseases and transplant nephrology. She was to continue tacrolimus ER $3 \mathrm{mg}$ QD PO and prednisone $5 \mathrm{mg}$ QD PO at home.

\section{Discussion}

There are multiple risk factors linked to CMV viremia and disease in SOTRs and after hematopoietic stem cell transplant. These include older age, female sex, blood group A, decreased creatinine clearance, allograft impairment, CMV serostatus prior to transplant (donor seropositive-recipient seronegative OR recipient seropositive), transplantation type, use of T-cell depleted stem cell grafts, use of anti-thymocyte globulin before transplant, and occurrence of graft-versus-host disease (GvHD) [2-6]. Vaccination has not been previously reported as a risk factor for CMV viremia.

The influenza virus vaccine administered seasonally is a trivalent or quadrivalent inactivated vaccine [1]. It is a $\mathrm{T}$ cell-dependent common recall antigen and has been shown to induce $\mathrm{T}$ cell activation and type 1 cytokine production (such as interleukin-2 and interferon- $\gamma$ ) [7]. There is a paucity of data on the effects of influenza vaccination leading to viremia in solid organ transplant recipients. Thus, we reviewed the data available in human immunodeficiency virus (HIV)-infected patients, another subset of immunocompromised patients.

The research on the effect of influenza virus on HIV replication has produced conflicting results. Some studies have shown that influenza vaccination results in increased HIV replication (and subsequently increased viremia) in patients with uncontrolled or partially controlled viral replication [7-10]. Other studies have shown that vaccination did not result in increased HIV replication [11-16]. It is believed that a transient increase in plasma HIV RNA levels occurs during the first and second weeks after vaccination - this may have been missed in some studies due to less frequent sampling [13]. A randomized controlled trial comparing the effect of vaccines (versus placebo) on HIV transcription and immune activation reported an increased HIV transcription, without increase in HIV DNA or plasma HIV RNA [17]. Vaccination is seen to produce a systemic inflammatory response - this may cause upregulation of viral production from chronically infected cells or activation of latently infected bystander cells $[8,18]$. This ultimately leads to an increase in RNA levels in patients who have ongoing low-level viral replication [8].

In some transplant recipients, influenza-like illness has been reported after vaccination [19]. SOTRs are maintained in a state of prolonged immunosuppression after transplant. Thus, there is a possibility that influenza vaccination may lead to transient increase in CMV viral load and subsequent viremia (similar to the transient viremia seen in HIV patients). The exact mechanisms leading to viremia are not known however the potential role of estrogen in transduction of CMV genes [2], as well as the effects of systemic inflammatory response (induced by vaccination) on viral replication $[8,18]$ indicate that molecular and genetic mechanisms may play a role.

Both patients had a temporal association of onset of CMV viremia with administration of the influenza 


\section{Cureus}

vaccine (Table 1). They were older females at high risk of CMV reactivation (donor CMV seropositive/recipient CMV seronegative). Patient 2 was on CMV prophylaxis, while patient 2 was not receiving valganciclovir (per our institutional protocol of CMV prophylaxis until six months posttransplant). They reported compliance with their home medications, with no recent increases in their maintenance immunosuppression. Patient 1 had an episode of antibody-mediated rejection, while patient 2 had an upper respiratory bacterial infection in the preceding months - these resolved completely with appropriate therapy. They had no concurrent inflammatory disease processes at the time of vaccination. Lab testing demonstrated high CMV DNA levels with concomitant leukopenia, neutropenia and lymphopenia.

There were no additional factors identified to have contributed to CMV viremia. The CMV viremia was severe enough to warrant therapeutic antiviral therapy and changes in their immunosuppression regimen. We thus believe that CMV viremia resulted from the prior vaccination in our patients.

\begin{tabular}{|c|c|c|c|}
\hline $\begin{array}{l}\text { Sr. } \\
\text { No. }\end{array}$ & Characteristic & Patient 1 & Patient 2 \\
\hline 1 & Type of donor & Living unrelated donor & Deceased donor \\
\hline 2 & $\begin{array}{l}\text { Initial transplant / Re- } \\
\text { transplant }\end{array}$ & Initial transplant & Re-transplant \\
\hline 3 & Donor CMV status & CMV seropositive & CMV seropositive \\
\hline 4 & Recipient CMV status & CMV seronegative & CMV seronegative \\
\hline 5 & $\begin{array}{l}\text { Induction } \\
\text { immunosuppressive regimen }\end{array}$ & $\begin{array}{l}\text { 1. Anti-thymocyte globulin 2. Methylprednisolone } 3 \text {. } \\
\text { IVIG }\end{array}$ & $\begin{array}{l}\text { 1. Anti-thymocyte globulin } 2 . \\
\text { Methylprednisolone }\end{array}$ \\
\hline 6 & $\begin{array}{l}\text { Recent inflammatory disease } \\
\text { processes (allograft } \\
\text { rejection, infection) }\end{array}$ & Donor-specific antibody mediated rejection & Upper respiratory infection \\
\hline 7 & $\begin{array}{l}\text { Time period between } \\
\text { transplant and inflammatory } \\
\text { disease process }\end{array}$ & 4 months & 1 month \\
\hline 8 & $\begin{array}{l}\text { Treatments for inflammatory } \\
\text { disease processes }\end{array}$ & 1. IVIG 2. Rituximab 3. Apheresis & Amoxicillin \\
\hline 9 & $\begin{array}{l}\text { Duration of inflammatory } \\
\text { disease process }\end{array}$ & 1 month & 1 week \\
\hline 10 & $\begin{array}{l}\text { Prior episodes of CMV } \\
\text { reactivation }\end{array}$ & None & None \\
\hline 11 & $\begin{array}{l}\text { Primary / Secondary CMV } \\
\text { prophylaxis }\end{array}$ & $\begin{array}{l}\text { Off CMV prophylaxis at the time of disease } \\
\text { presentation }\end{array}$ & Primary prophylaxis \\
\hline 12 & $\begin{array}{l}\text { Recent increase in } \\
\text { maintenance } \\
\text { immunosuppressive regimen }\end{array}$ & None & None \\
\hline 13 & Age at time of presentation & 55 years & 62 years \\
\hline 14 & $\begin{array}{l}\text { Time period between } \\
\text { transplant and presentation }\end{array}$ & 17 months & 3 months \\
\hline 15 & $\begin{array}{l}\text { Time period between } \\
\text { vaccination and presentation }\end{array}$ & 8 days & 7 days \\
\hline 16 & $\begin{array}{l}\text { Prophylactic medications at } \\
\text { the time of presentation }\end{array}$ & SMX-TMP SS 1 tablet PO QD & $\begin{array}{l}\text { SMX-TMP SS } 1 \text { tablet PO QOD } \\
\text { Valganciclovir } 450 \mathrm{mg} \text { QD }\end{array}$ \\
\hline 17 & $\begin{array}{l}\text { Immunosuppressive regimen } \\
\text { at the time of presentation }\end{array}$ & $\begin{array}{l}\text { Prednisone } 5 \text { mg PO QD MMF } 360 \text { mg PO QID } \\
\text { Tacrolimus } 0.5 \text { mg PO BID }\end{array}$ & $\begin{array}{l}\text { Prednisone } 5 \text { mg QD MMF } 1000 \text { mg BID } \\
\text { Tacrolimus ER } 8 \text { mg QD }\end{array}$ \\
\hline 18 & Initial symptoms & $\begin{array}{l}\text { Fevers, chills, night sweats lethargy, headaches, } \\
\text { myalgias, nausea, anorexia, pleuritic chest pain } \\
\text { watery, non-bloody diarrhea }\end{array}$ & Watery, non-bloody diarrhea \\
\hline & Initial laboratory & WBC $2,070 / \mathrm{mm}^{3}$ ANC $1,865 / \mathrm{mm}^{3}$ Platelets & WBC $1,480 / \mathrm{mm}^{3}$ ANC $950 / \mathrm{mm}^{3}$ \\
\hline
\end{tabular}




\section{Cureus}

Initial lymphocyte count [N: $1,000-3,300 / \mathrm{mm}^{3}$ ]

CMV viral load [lower limit of

21 assay detection: $60 \mathrm{IU} / \mathrm{ml}$ (1.78 log10 IU/ml)]

22 Treatment regimen

Changes in immunosuppressive regimen

Patient outcome 108,000/mm ${ }^{3}$ AST 81 IU/I ALT 87 I U/I ALP 137 IU/I

$500 / \mathrm{mm}^{3}$

$154,697 \mathrm{IU} / \mathrm{ml}$ (5.19 log10 IU/ml)

Valganciclovir 900 mg PO BID

Temporary discontinuation of MMF

Control of CMV viremia and recovery of cell counts

Stable allograft function
Hemoglobin $11.1 \mathrm{~g} / \mathrm{dl}$ BUN $20 \mathrm{mg} / \mathrm{dl}$ Creatinine $1.53 \mathrm{mg} / \mathrm{dl}$ ALP $124 \mathrm{IU} / \mathrm{I}$

$270 / \mathrm{mm}^{3}$

$214,823 \mathrm{IU} / \mathrm{ml}(5.33 \mathrm{log} 10 \mathrm{IU} / \mathrm{ml})$

1. Ganciclovir $2.5 \mathrm{mg} / \mathrm{kg}$ IV QD (initial dosing) 2. Letermovir $480 \mathrm{mg}$ PO QD

1. Temporary discontinuation of MMF 2. Decrease in Tacrolimus dosing (Tacrolimus ER 3 mg QD PO)

Control of CMV viremia and recovery of cell counts

Stable allograft function

\section{TABLE 1: Patient characteristics}

ALT: Alanine transaminase; ANC: Absolute neutrophil count; ALP: Alkaline phosphatase; AST: Aspartate transaminase; BID: Every 12 hours; BUN: Blood urea nitrogen; CMV: Cytomegalovirus; ER: Extended release; IV: Intravenous; IVIG: Intravenous immune-globulin; PO: Oral; QD: Every twentyfour hours; QID: Every six hours; QOD: Every forty-eight hours; SMX-TMP: Sulfamethoxazole-trimethoprim; SS: Single-strength; WBC: White blood cell count.

One meta-analysis concluded that the influenza vaccine was associated with statistically significant protection against influenza-like illness in immunocompromised patients, including SOTRs [20]. Given the significant proven benefits of vaccination in SOTRs (versus the risk of potential viremia), we firmly believe that all SOTRs should get the inactivated influenza vaccine and other vaccines as per the latest guidelines [1]. Through this case report, we wish to highlight the finding of CMV viremia occurring after influenza vaccination, with no other identified triggers. Further research and accumulation of cases is needed to investigate the strength of this association, to determine the mechanisms that resulted in CMV viremia and to recognize the risk factors leading to progression from viremia to clinically relevant CMV disease.

\section{Conclusions}

Vaccination may lead to transient viral replication in immunocompromised patients, such as HIV-infected patients (likely due to genetic and immune-mediated mechanisms). Similarly, we believe that influenza vaccination led to transient CMV viremia and CMV disease in our renal transplant recipients on potent immunosuppressive therapies. Further research is needed to assess the strength of this correlation, the mechanisms causing viremia and the risk of progression to clinical disease. Until then, clinicians must continue vaccination of SOTRs per the guidelines, but must also remember to enquire about recent vaccination when evaluating SOTRs with new onset CMV viremia.

\section{Additional Information}

\section{Disclosures}

Human subjects: Consent was obtained by all participants in this study. Not applicable issued approval Not applicable. The research met our institutional definition of a case report (a medical chart review of 3 or fewer patients). Thus institutional research board review was not needed and the need for consent was waived. Conflicts of interest: In compliance with the ICMJE uniform disclosure form, all authors declare the following: Payment/services info: All authors have declared that no financial support was received from any organization for the submitted work. Financial relationships: All authors have declared that they have no financial relationships at present or within the previous three years with any organizations that might have an interest in the submitted work. Other relationships: All authors have declared that there are no other relationships or activities that could appear to have influenced the submitted work.

\section{References}

1. Danziger-Isakov L, Kumar D; AST ID Community of Practice: Vaccination of solid organ transplant candidates and recipients: guidelines from the American society of transplantation infectious diseases community of practice. Clin Transplant. 2019, 33:13563. 10.1111/ctr.13563

2. Freeman RB, Paya C, Pescovitz MD, et al.: Risk factors for cytomegalovirus viremia and disease developing after prophylaxis in high-risk solid-organ transplant recipients. Transplantation. 2004, 78:1765-1773. 
10.1097/01.tp.0000142619.01510.a5

3. Khoury JA, Storch GA, Bohl DL, et al.: Prophylactic versus preemptive oral valganciclovir for the management of cytomegalovirus infection in adult renal transplant recipients. Am J Transplant. 2006, 6:2134-2143. 10.1111/j.1600-6143.2006.01413.x

4. Abbott KC, Hypolite IO, Viola R, et al.: Hospitalizations for cytomegalovirus disease after renal transplantation in the United States. Ann Epidemiol. 2002, 12:402-409. 10.1016/s1047-2797(01)00283-6

5. Wu JL, Ma HY, Lu CY, et al.: Risk factors and outcomes of cytomegalovirus viremia in pediatric hematopoietic stem cell transplantation patients. J Microbiol Immunol Infect. 2017, 50:307-313. 10.1016/j.jmii.2015.07.011

6. Einollahi B: Cytomegalovirus infection following kidney transplantation: a multicenter study of 3065 cases . Int J Organ Transplant Med. 2012, 3:74-78.

7. Vigano A, Bricalli D, Trabattoni D, et al.: Immunization with both $\mathrm{T}$ cell-dependent and $\mathrm{T}$ cell-independent vaccines augments HIV viral load secondarily to stimulation of tumor necrosis factor alpha. AIDS Res Human Retroviruses. 1998, 14:727-734. 10.1089/aid.1998.14.727

8. Günthard HF, Wong JK, Spina CA, et al.: Effect of influenza vaccination on viral replication and immune response in persons infected with human immunodeficiency virus receiving potent antiretroviral therapy. J Infect Dis. 2000, 181:522-531. 10.1086/315260

9. Ramilo O, Hicks PJ, Borvak J, et al.: T cell activation and human immunodeficiency virus replication after influenza immunization of infected children. Pediatr Infect Dis J. 1996, 15:197-203. 10.1097/00006454199603000-00004

10. Kosalaraksa P, Srirompotong U, Newman RW, Lumbiganon P, Wood JM: Serological response to trivalent inactive influenza vaccine in HIV-infected children with different immunologic status. Vaccine. 2011, 29:3055-3060. 10.1016/j.vaccine.2011.01.091

11. Fowke KR, D'Amico R, Chernoff DN, et al.: Immunologic and virologic evaluation after influenza vaccination of HIV-1-infected patients. AIDS. 1997, 11:1013-1021. 10.1097/00002030-199708000-00010

12. Glesby MJ, Hoover DR, Farzadegan H, Margolick J, Saah AJ: The effect of influenza vaccination on human immunodeficiency virus type 1 load: a randomized, double-blind, placebo-controlled study. J Infect Dis. 1996, 174:1332-1336. 10.1093/infdis/174.6.1332

13. Fuller JD, Craven DE, Steger KA, Cox N, Heeren TC, Chernoff D: Influenza vaccination of human immunodeficiency virus (HIV)-infected adults: impact on plasma levels of HIV type 1 RNA and determinants of antibody response. Clin Infect Dis. 1999, 28:541-547. 10.1086/515170

14. Onlamoon N, Unpol P, Boonchan M, et al.: Immune activation and viral replication after vaccination with an influenza A H1N1 2009 vaccine in HIV-infected children receiving antiretroviral therapy. Dis Markers. 2013, 35:7. 10.1155/2013/276547

15. Tasker SA, Treanor JJ, Paxton WB, Wallace MR: Efficacy of influenza vaccination in HIV-infected persons: a randomized, double-blind, placebo-controlled trial. Ann Intern Med. 1999, 131:430-433. 10.7326/00034819-131-6-199909210-00006

16. Skiest DJ, Machala T: Comparison of the effects of acute influenza infection and influenza vaccination on HIV viral load and CD4 cell counts. J Clin Virol. 2003, 26:307-315. 10.1016/s1386-6532(02)00047-1

17. Yek C, Gianella S, Plana M, et al.: Standard vaccines increase HIV-1 transcription during antiretroviral therapy. AIDS. 2016, 30:2289-2298. 10.1097/QAD.0000000000001201

18. Tsai MY, Hanson NQ, Straka RJ, et al.: Effect of influenza vaccine on markers of inflammation and lipid profile. J Lab Clin Med. 2005, 145:323-327. 10.1016/j.lab.2005.03.009

19. Madan RP, Tan M, Fernandez-Sesma A, Moran TM, Emre S, Campbell A, Herold BC: A prospective, comparative study of the immune response to inactivated influenza vaccine in pediatric liver transplant recipients and their healthy siblings. Clin Infect Dis. 2008, 46:712-718. 10.1086/527391

20. Beck CR, McKenzie BC, Hashim AB, Harris RC; University of Nottingham Influenza and the ImmunoCompromised (UNIIC) Study Group, Nguyen-Van-Tam IS: Influenza vaccination for immunocompromised patients: systematic review and meta-analysis by etiology. J Infect Dis. 2012, 206:1250-1259. 10.1093/infdis/jis487 